\title{
IDENTIFICAÇÃO POST-MORTEM BASEADA NA ANÁLISE DA ARACDA DENTAL- RELATO DE CASO
}

\author{
Naiara de Oliveira Pereira ${ }^{1}$ \\ Antonio Carlos Victor Canettieri ${ }^{2}$
}

Resumo: Em 2003, ocorreu uma explosão na Base do Veículo Lançador de Satélites em Alcântara, no estado do Maranhão, que provocou 21 vítimas fatais, todas carbonizadas. O presente trabalho visou relatar uma simulação do processo de identificação de uma das vítimas, por meio da comparação dos dados do prontuário odontológico desenvolvido pelos cirurgiões dentistas do DCTA e de informações presentes no laudo de identificação elaborado pelos legistas do Maranhão. Como também, demonstrar a importância do preenchimento detalhado do odontograma e do cuidado com o feitio e arquivamento das imagens radiográficas e de todos os documentos odontológicos, que poderiam levar ao reconhecimento de um indivíduo. No confronto entre os registros AM e PM foram encontradas 06 similaridades, 12 discrepâncias e nenhuma incompatibilidade, permitindo associar positivamente a identidade da vítima ao corpo examinado. Esse processo teria sido facilitado se dados relacionados ao tipo de material restaurador e às faces envolvidas na restauração tivessem sido registrados com detalhes.

Palavras-chave: Identificação Humana; Prontuários; Odontologia Legal; Antropologia forense.

\footnotetext{
1 Odontologia/Universidade do Vale do Paraíba, Brasil. E-mail: naiara.op@gmail.com.

2 Odontologia/Universidade do Vale do Paraíba, Brasil. E-mail: acanettieri@gmail.com.
} 